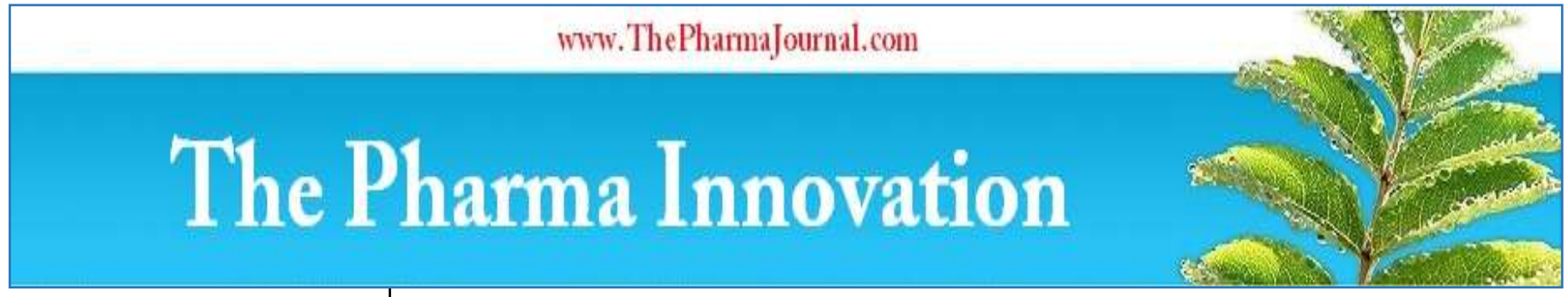

ISSN (E): 2277- 7695

ISSN (P): 2349-8242

NAAS Rating: $\mathbf{5 . 2 3}$

TPI 2021; 10(4): 685-688

(C) 2021 TPI

www.thepharmajournal.com

Received: 22-02-2021

Accepted: 24-03-2021

\section{E Tharuntej}

Scientific Officer at Palamuru

Biosciences, Telangana, India

\section{N Rajanna}

Professor, Department of

Livestock Production

Management, College of

Veterinary Science, PVNR TVU,

Rajendrangar, Hyderabad,

Telangana, India

\section{A Sarat Chandra}

Professor \& Head Department of

Livestock Production

Management, College of

Veterinary Science, PVNR TVU,

Rajendrangar, Telangana, India

D Nagalakshmi

Professor \& Univ. Head

Department of Animal

Nutrition, College of Veterinary

Science, PVNR TVU,

Rajendrangar, Hyderabad,

Telangana, India
Corresponding Author:

N Rajanna

Professor, Department of

Livestock Production

Management, College of

Veterinary Science, PVNR TVU,

Rajendrangar, Hyderabad,

Telangana, India

\section{A study on behaviour of Deccani lambs reared on different flooring material}

\author{
E Tharuntej, N Rajanna, A Sarat Chandra and D Nagalakshmi
}

DOI: https://doi.org/10.22271/tpi.2021.v10.i4j.6037

\begin{abstract}
A study was conducted to evaluate the behaviour of Deccani lambs on different flooring material. Behaviour is the important indicator of animal welfare. Eighteen growing Deccani lambs of either sex with uniform body weight of $12.61 \pm 0.04 \mathrm{~kg}$ and aged between 3 to 6 months were selected from the Sheep and Goat unit of Livestock Farm complex. These lambs were randomly allotted to three flooring types viz., Mud floor (control, T1), Concrete floor (T2) and mud floor with rubber mats (black, rubber material, $8 \mathrm{~mm}$ thick (T3). The behaviour of lambs was recorded with help of Video cameras and digital video recorder (model: DS - 7B04HQHI-K1). The data on standing time (min) and percentage of standing was significantly $(P<0.01)$ higher on concrete floor than mud and rubber mat floors. Resting time $(\mathrm{min})$ and percentage was significantly $(P<0.05)$ higher on the rubber mat floor than on the concrete. Eating, drinking and licking behaviour were similar among the three flooring materials. It was noticed that lambs reared on rubber mat floor were more comfortable than other two flooring material, hence this can be used an alternate flooring material to rear the sheep in intensive farming.
\end{abstract}

Keywords: Deccani lambs, behaviour, different flooring material

\section{Introduction}

Sheep rearing is an important livelihood activity of small, marginal and landless farmers in the country. Sheep withstand the semi-arid and arid conditions and comes up very well even in quality of grazing resources and water is scarce.

As per the 20th Livestock Census (2019), the sheep population in India is 74.26 million and contributes $13.87 \%$ of the total livestock population. India ranks third in the world sheep population with $6.8 \%$ of the world population and contributing to $4.9 \%$ of total meat production in the country. Telangana state is known for its diversified livestock resources. It ranked first in the sheep population with 19.1 million and contributing $25.72 \%$ of the total sheep population in India (D.A.H., GOI, 2019) ${ }^{[4]}$. Small ruminant farming is the livelihood of nearly 5.32 lakh families in the state. Telangana is the home tract of the Deccani breed of sheep which is well-known for its hardiness and well adopted critical climatic conditions even in inadequate water and fodder availability.

In Telangana, sheep are generally reared in extensive system but due to decreasing grazing resources, farmers are showing interest to rear the sheep commercially either in semi-intensive or intensive system. In these systems, housing plays a key role in lamb management. Lambs are precious assets to the shepherds and the post weaning growth rate mainly depends upon the proper housing management. An ideal housing enables in moderating the range of microclimate to which the animals are exposed and the wellbeing varies upon the forms of housing and floor in which they are kept. The wellness of the animals mainly exhibited in the form of behaviour. Behaviour is one of the most commonly used and sensitive indicators of animal welfare. The behaviour of animals will change in response to the situations they are in and the handling experience, resulting in an increased or decreased frequency of common behaviours. Therefore, the present study was carried out to assess behaviour of lambs of growing Deccani lambs on the different flooring materials.

\section{Materials and Methods}

The study was conducted in Sheep and Goat unit of Livestock Farm Complex, College of Veterinary Science, and Hyderabad. Hyderabad city lies at $17.366^{\circ} \mathrm{N}$ latitude and $78.476^{\circ} \mathrm{E}$ longitude in the Deccan Plateau and rises to an average height of $536 \mathrm{~m}$ above the sea level. The climate of the Hyderabad is unique which has a combination of a tropical wet and dry climate that borders on a hot semi-arid climate. 
Eighteen growing lambs of either sex with uniform body weight of $12.61 \pm 0.04 \mathrm{~kg}$ and aged between 3 to 6 months were selected from Sheep and Goat unit of LFC and randomly allotted to three flooring types viz., Mud floor (control, T1), Concrete floor (T2) and mud floor with rubber mats (black, rubber material, $8 \mathrm{~mm}$ thick (T3). All the lambs in the experiment were housed under conventional housing provided with a floor space of $1 \mathrm{~m}^{2} / \mathrm{lamb}$ in the covered shed with an asbestos roof. All the animals in three groups were fed with concentrate mixture as per the ICAR (2013) ${ }^{[6]}$ plus ad-libitum green fodder (para grass) twice in a day, 8 AM and 3 PM. The study was conducted from April to July 2019 (90 days). All animals were dewormed with Albendazole @ $10 \mathrm{mg} / \mathrm{kg}$ body weight before start of the experiment and allowed a seven days acclimatization on the same flooring materials before start of the experiment. Behaviour of lambs were recorded during the quietest period of the day ( 6 am to $6 \mathrm{pm}$ ) with the help of Video cameras. One video camera was placed in front of each pen about $1.8 \mathrm{~m}$ above the ground. All the pens were recorded for three days i.e., on July $4^{\text {th }}, 5^{\text {th }}$ and $6^{\text {th }} 2019$ during the study period. When analysing the videotapes, the behaviour and position in the pen were scored using instantaneous scan sampling at 10 minutes intervals with the help of digital video recorder (model: DS - 7B04HQHI-K1) which was set up in a room close to the pens. All videos were watched by the same trained observer. The recorded behavioural activities were Standing: Lamb standing on all four legs, Eating: Lamb searching for feed in the trough and eating it, Drinking: Lamb drinking water from the drinker, Lying: Lamb resting on the lower hind leg and thigh, abdomen and front legs and Licking: Lamb licking their body parts.

The data were analysed for frequency, percentage, one-way analysis of variance (Snedecor and Cochran, 1994) ${ }^{[13]}$ and comparison of means of different treatment groups was made by Duncan's multiple range test (Duncan, 1955) ${ }^{[5]}$ using SPSS statistical software (version 25.0; SPSS, 2019).

\section{Results and Discussion}

Behaviour of Deccani lambs reared on different flooring material is shown in Table 1

\section{Standing}

The standing time $(\mathrm{min})$ and percentage of time was 211.61 $\pm 6.66,243.00 \pm 6.35$ and $189.72 \pm 8.51$ and $29.39 \pm 0.92$, $33.75 \pm 0.88$ and $26.35 \pm 1.18$ in mud, concrete and rubber mat floors, respectively. There was significant difference $(P<0.05)$ of standing time $(\mathrm{min})$ and percentage of time of lambs in three flooring systems (Table 1). The highest standing time $(\mathrm{min})$ and percentage was recorded in concrete floor followed by mud and rubber mat floors. This could be due to the less lying comfort on the concrete floor compared to other two floorings. The results were in accordance with Di Grigoli et al. (2003) [8], Bhakat and Nagpaul (2011) [1], Teixeira et al. (2015) ${ }^{[15]}$ and Monali Bhaskar (2018) ${ }^{[12]}$ who reported that the percentage of time spent on standing was significantly influenced by flooring type. Hannien et al. (2005) [9], Hansen et al. (2012) ${ }^{[10]}$ and Deshmukh (2017) [7] reported the percentage of time spent during standing was not influenced by flooring type and there was no significant difference among the groups.

\section{Eating}

The eating time (min) and percentage of time was
$148.98 \pm 4.24,152.59 \pm 4.90$ and $157.53 \pm 5.82$ and $20.69 \pm 0.59$, $21.19 \pm 0.68$ and $22.05 \pm 0.56$ in mud, concrete and rubber mat floors, respectively. Statistical analysis of the data on eating revealed a non-significant difference among the treatments for time (min) and percentage of time spent on eating (Table 1). Relatively more time (min) and percentage of time was spent by the lambs on eating on the rubber fat floor followed by the concrete and mud floors.

Rumination (eating) is important physiological behaviour of animals which indicates the sound health, perfect digestion and comfort of animal in turn body weight and average daily gain. Similar findings were reported by Di Grigoli et al. (2003) ${ }^{[8]}$, Boe et al. (2007) [2], Kartal and Yanar (2011) [11] and Cozzi et al. (2013) ${ }^{[3]}$ who reported the percentage of time spent on eating was not influenced by the flooring type and there was no significant difference between the groups.

\section{Drinking}

Statistical analysis of the data showed a non-significant difference among the treatments for time (min) and percentage of time spent on drinking. Flooring type had no effect on drinking behaviour. The present findings are in agreement with Bhakat and Nagpaul (2011) ${ }^{[1]}$ and Teixeira et al. (2015) [15] who reported that drinking behaviour was similar in all groups and flooring type had no effect on drinking behaviour.

\section{Lying}

An increased resting time (Lying) may result in better quality sleep that leads to an altered growth hormone secretion and improved growth. The lying (min) and percentage of time was $350.59 \pm 10.52, \quad 315.02 \pm 11.12$ and $362.34 \pm 13.80$ and $48.75 \pm 1.03,43.77 \pm 1.22$ and $50.72 \pm 0.14$ in mud, concrete and rubber mat floors, respectively. Statistical analysis of the present study showed a significant $(P<0.05)$ difference among the three flooring systems for time $(\mathrm{min})$ and percentage of time spent on lying. The mean percentage of time spent on lying was significantly $(P<0.05)$ lower in concrete floor than mud and rubber mat floors (Table 1).

The result of present study indicated that concrete floor provided less lying comfort when compared to mud and rubber mat floors to lambs. This result could be attributed to the dirty and wet flooring type which might result in discomfort for the lambs on the concrete floor. These results were corroborated with the findings of Stefanowska, et al. (2002) ${ }^{[14]}$, Di Grigoli et al. (2003) ${ }^{[8]}$, Boe et al. (2007) ${ }^{[2],}$ Bhakat and Nagpaul (2011) [1], Teixeira et al. (2015) [15], Monali Bhaskar (2018) reported that the amount of time spent lying varied significantly according to the type of flooring in all trials. In contrast to the present findings, Hannien et al. (2005) ${ }^{[9]}$, Hansen et al. (2012) ${ }^{[10]}$ and Deshmukh (2017) reported that the percentage of time spent on lying was not influenced by flooring type and there was no significant difference between the groups.

\section{Licking}

Licking is often associated with a social behaviour of animals. Statistical analysis of the data showed that the time (min) and percentage of time spent on licking was similar in all treatment groups and flooring type had no effect on licking behaviour.

The overall mean percentage of time spent on licking was higher in concrete and rubber mat floors when compared with mud floor (Table 1). 
The higher frequency of licking in lambs might be due to vigorous social interaction between the pen mates. The results obtained in the present study are non-comparable as the literature on licking behaviour of Deccani lambs on different flooring systems was scanty.

\section{Acknowledgments}

Authors are thankful to the University Officers of P.V. Narsimha Rao Telangana Veterinary University, Hyderabad, Telangana, India for according permission to carry out the research work.

Table 1: Behaviour of Deccani lambs reared on different flooring material

\begin{tabular}{|c|c|c|c|c|c|}
\hline Behaviour & Mud floor (T1) & Concrete floor (T2) & Mud floor with rubber mats (T3) & SEM & P-Value \\
\hline \multicolumn{6}{|c|}{ Standing** } \\
\hline Time & $211.62 \pm 6.66^{\mathrm{b}}$ & $243.04 \pm 6.35^{\mathrm{a}}$ & $189.76 \pm 8.51^{\mathrm{c}}$ & 0.916 & 0.001 \\
\hline Percent & $29.39 \pm 0.92^{\mathrm{b}}$ & $33.75 \pm 0.88^{\mathrm{c}}$ & $26.35 \pm 1.18^{\mathrm{a}}$ & 0.916 & 0.001 \\
\hline \multicolumn{6}{|c|}{ Eating } \\
\hline Time & $148.98 \pm 4.24$ & $152.59 \pm 4.90$ & $157.53 \pm 5.82$ & 0.403 & 0.401 \\
\hline Percent & $20.69 \pm 0.59$ & $21.19 \pm 0.68$ & $22.05 \pm 0.56$ & 0.403 & 0.401 \\
\hline \multicolumn{6}{|c|}{ Drinking } \\
\hline Time & $5.38 \pm 0.15$ & $5.82 \pm 0.13$ & $5.60 \pm 0.22$ & 0.014 & 0.222 \\
\hline Percent & $0.75 \pm 0.02$ & $0.81 \pm 0.02$ & $0.78 \pm 0.03$ & 0.014 & 0.222 \\
\hline \multicolumn{6}{|c|}{ Lying* } \\
\hline Time & $350.59 \pm 10.52^{\mathrm{ab}}$ & $315.02 \pm 11.12^{\mathrm{a}}$ & $362.34 \pm 13.80^{\mathrm{b}}$ & 1.129 & 0.035 \\
\hline Percent & $48.75 \pm 1.03^{\mathrm{a}}$ & $43.77 \pm 1.22^{\mathrm{b}}$ & $50.72 \pm 0.14^{\mathrm{a}}$ & 1.129 & 0.035 \\
\hline \multicolumn{6}{|c|}{ Licking } \\
\hline Time & $3.23 \pm 0.05$ & $3.41 \pm 0.12$ & $3.37 \pm 0.09$ & 0.007 & 0.372 \\
\hline Percent & $0.45 \pm 0.01$ & $0.47 \pm 0.02$ & $0.47 \pm 0.01$ & 0.007 & 0.372 \\
\hline
\end{tabular}

a, b, c Means with different superscripts row wise differ significantly at $P<0.05 ; P<0.01$
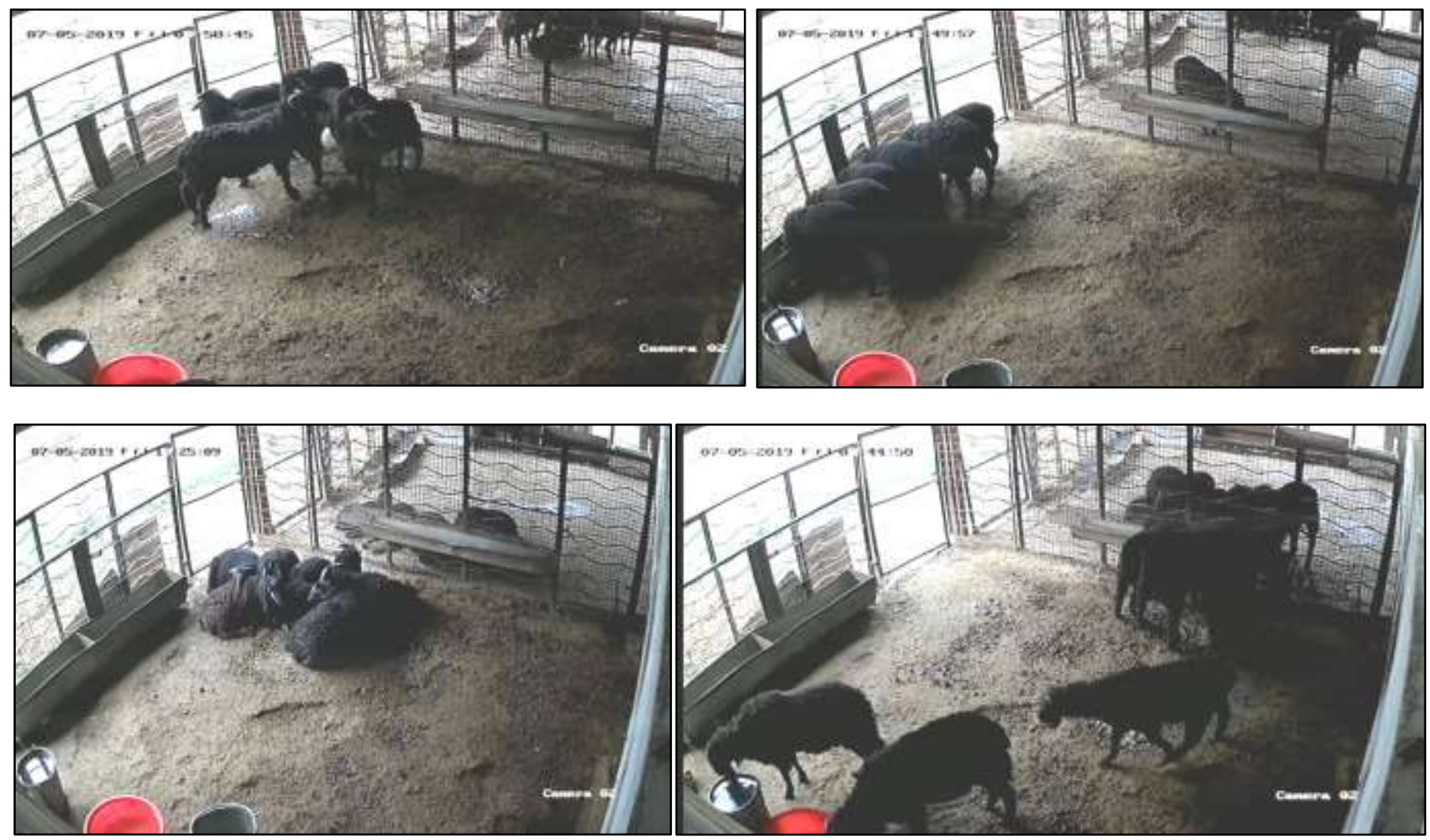

Fig 1: Standing, Eating, Drinking and Lying behaviours of Deccani lambs on mud floor

\section{References}

1. Bhakat C, Nagpaul PK. Growth of female kids under different housing systems. Indian Veterinary Journal 2011;88(7):59-61.

2. Boe KE, Andersen IL, Buisson L, Simensen E, Jeksrud WK. Flooring preferences in dairy goats at moderate and low ambient temperature. Applied animal behaviour science 2007;108(1):45-57.

3. Cozzi G, Tessitore E, Contiero B, Ricci R, Gottardo F,
Brscic M. Alternative solutions to the concrete fullyslatted floor for the housing of finishing beef cattle: effects on growth performance, health of the locomotors system and behaviour. The Veterinary Journal 2013;197(2):211-215.

4. DAH. Department of Animal Husbandry, Government of India, 2019. Key note $20^{\text {th }}$ Livestock Census.

5. Duncan DB. Multiple range and multiple $\mathrm{F}$ tests. Biometrics 1955;11(1):1-42. 
6. ICAR. Indian Council of Agricultural Research. Nutrient requirements for Sheep, Goat and Rabbit 2013.

7. Deshmukh AK. Growth performance of Madgyal lambs under different housing system; Thesis submitted to Maharashtra Animal \& Fishery Sciences University, Nagpur-440001, Maharashtra state, India 2017.

8. Di Grigoli A, Bonanno A, Alabiso M, Russo G, Leto G. Effects of housing system on welfare and milk yield and quality of Girgentana goats. Italian Journal of Animal Science 2003;2(1):542-544.

9. Hanninen L, De Passille AM, Rushen J. The effect of flooring type and social grouping on the rest and growth of dairy calves. Applied Animal Behaviour Science, 2005;91(3-4):193-204.

10. Hansen GHM, Jorgensen V, Lind, Uhlig C. Woodchip bedding for sheep in Northern Norway. Acta Agriculturae Scand Section A 2012;62(2):102-110.

11. Kartal TZ, Yanar M. Effect of floor types on the growth performance and some behavioural traits of Brown Swiss calves. Veterinarijair Zootechnika 2011;55(77):20-24.

12. Monali Bhaskar. Growth Zootechnika performance of Osmanabadi kids under different housing systems. Thesis submitted to Maharashtra Animal \& Fishery Sciences University, Parbhani, Maharashtra state, India 2018.

13. Snedecor GW, Cochran WG. Statistical methods. 8th edition. Affiliated East. West Press, New Delhi 1994;13:1467-1473.

14. Stefanowska J, Swierstra D, Smits AC, Berg JVD, Metz JHM. Reaction of calves to two flooring materials offered simultaneously in one pen. Acta Agriculturae Scandinavica, Section A-Animal Science 2002;52(2):5764.

15. Teixeira DL, Miranda-de la Lama G, Villarroel M, Olleta, JL, García-Belenguer S, Escos J, et al. Effects of alternative bedding substrates on lamb welfare, productive performance, and meat quality during the finishing phase of fattening. Journal of Veterinary Behaviour 2015;10(2):171-178. 